Article

\title{
Exploring a Third Space for Sustainable Educational Development-HIV/AIDS Prevention, Zambia
}

\section{Ellen Carm}

Department of International Studies and Interpreting, Faculty of Education, OsloMet University, PB 4 St. Olavs plass, Oslo NO-0130, Norway; Ellen.Carm@hioa.no; Tel.: +47-67-23-72-18 or +47-97-72-01-23

Received: 4 January 2018; Accepted: 19 March 2018; Published: 23 March 2018

Abstract: This study was conducted in Zambia from 2002 to 2008, a country greatly affected by the HIV (Human Immunodeficiency Virus)/AIDS (Acquired Immune Deficiency Syndrome) epidemic. The global, national, as well as local discourses on spread and mitigation were clustered around scientific knowledge and the local context and cultural traditions. The education sector struggled with implementing the national HIV/AIDS education strategy but by a broader stakeholder involvement, and a close collaboration between the educational sector and tribal chiefs and their traditional internal structures, a localized approach emerged. The overall objective of the paper is to illustrate how a multi-voiced strategy can bring about sustainable change, illustrated by this study. The study used qualitative constructivist and grounded theoretical approaches, and applied the third generation of cultural and historical activity theory (CHAT) as an analytical tool. Bernstein's concept, symbolic control, contributes to a broader understanding of the underlying processes and outcomes of the study. The findings revealed that the strategically monitored multi-voiced participation of local stakeholders created a learning space where both scientific and indigenous knowledge were blended, and thereby creating solutions to preventive action meeting the local needs. The study exemplifies these processes by identifying contradictions between the various levels and activity systems involved, by listing some of their characteristics, manifestations and finally their negotiated solutions. These solutions, or the third space interventions, the outcome of the multi-voiced participation, is in the paper used to explore a theoretical framework for an ethical and decolonized development strategy; a precondition for sustained local development.

Keywords: multi-, levelled and voiced strategy; decolonized approach; HIV/AIDS prevention; localization; transformation; cultural historical activity theory; Western and Indigenous epistemologies; third space; sustainable development

\section{Introduction}

This case study explored how behavioral change and cultural transformation was initiated and developed "from within". The paper draws upon findings revealed by Carm [1], a study built upon a HIV/AIDS education prevention intervention in one province in Zambia, from 2002 to 2008, comprising 13 districts, building upon the national policies and strategies, Ministry of Education (MOE, [2-4]). The research context was complex, where commitment to change was intertwined with cultural resistance, critique, and ambiguity, and where the various participants and stakeholders, from educationist and professionals at different levels, nongovernmental (NGOs) actors, to tribal leaders and villagers, were explicating new possibilities, and envisioning new patterns, behavior and models of activity. Thus, CHAT and expansive learning (Engeström $[5,6])$. were applied to deconstruct dialogue and negotiations to unveil the processes of change, discussed with the lenses of Bernstein $[7,8]$, through his theory of regulatory and symbolic control. The baseline surveys revealed a polyphony of contradictions between global and national policies and strategies, and the actual local implementation 
of HIV / AIDs prevention education. In contrast, the multi-voiced approaches applied at district, school and community level identified issues and possible solutions, and revealed factors that led to a diverse set of localized solutions to HIV/AIDS prevention at the school and community level. The processes at play and the final outputs of the interventions cut across the borders of formal and informal organizational and individual learning (here, implicit and explicit learning), and illustrates some of the dilemmas inherent in external aid for development.

\section{Materials and Methods}

\subsection{Research Methods}

Qualitative and interpretivist research was conducted within a constructivist grounded theoretical approach (Charmaz, 2003 [9]). The study applied comparative, multilayered, and longitudinal perspectives, while utilizing a broad range of methods. Documentary analyses, and structured and semi-structured interviews were conducted, and in-depth conversations with traditional or tribal leaders, also termed chiefs, educational administrators, leaders, teachers, parents, and pupils were all carried out during the study period. Table 1 gives an overview of the project activities and interventions.

Relevant stakeholders from MOE, at national, province, district and school levels, as well as NGO representatives, local leaders, chiefs, and villagers (comprising parents and pupils), including lecturers and staff from a teacher training college, all from the first two districts involved (A), participated in a broad-based conference, 2002, indicated in Figure 1 as a circle. Each group of stakeholders presented their views and experiences on impacts of HIV / AIDS, as well as drivers of the epidemic. After discussions and negotiations, a common vision was agreed upon, and a strategy comprising training and local implementation was agreed upon. The implementation took place the same year, indicated by a square, Figure 1. The agreed monitoring and evaluation strategies was shared, discussed, and revised according to needs, among the main actors from the first cohort in 2003, indicated by a triangle, The same year, a conference comprising a gathering of the same actors from another three districts (B) were conducted (see the circle at 2003). Their agreed strategies followed a fairly similar framework as for group A, but had slightly different components and activities, based upon the local needs and diverse context. The implementation, B, took place during 2003, but for the monitoring and evaluation, 2004, all core stakeholders, from A and B jointly took part in the monitoring and evaluation, sharing ideas and strategies, see the triangle comprising A and B in 2004.

\begin{tabular}{|c|c|c|c|c|c|}
\hline Cohorts/Year & 2002 & 2003 & 2004 & 2005 & 2006 \\
\hline A: 2 districts & 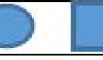 & & & & \\
\hline B: 3 district & & & & & \\
\hline C: 3 districts & & & & & \\
\hline D: 3 districts & & & & & \\
\hline
\end{tabular}

Figure 1. Overview of the activities and implementation over the program period.

During the application to cohort $\mathrm{C}$ and $\mathrm{D}$, the same multi-voiced pattern was utilized. These various interventions gave voice to the different stakeholders, different lenses were applied, and the learning took place across traditional boarders between the actors involved.

The data was gathered through different methodological tools, as written previously. The sources of data can be seen in Table 1. 
Table 1. Overview of the various data tools and main documents.

\begin{tabular}{lllll}
\hline Year & Policy/Documents & Surveys & Field Notes & Reports/Minutes \\
\hline 2002 & $\begin{array}{l}\text { Educating our Future } \\
\text { (MOE, 1996) }\end{array}$ & $\begin{array}{l}\text { Baseline, School } \\
\text { Mapping, interviews }\end{array}$ & Workshops and school visits & Meetings, workshops, school visits \\
\hline 2002 & $\begin{array}{l}\text { HIV/AIDS education } \\
\text { prevention, syllabus } \\
\text { guidelines (MOE, 2002) }\end{array}$ & $\begin{array}{l}\text { Open interviews, district and } \\
\text { school level employees }\end{array}$ & $\begin{array}{l}\text { Multivoiced } \\
\text { Planning Conference, workshops }\end{array}$ & $\begin{array}{l}\text { Reports, planning conference, } \\
\text { and workshops }\end{array}$ \\
\hline \multirow{2}{2003-2006}{$\begin{array}{l}\text { Interactive Methodology } \\
\text { for HIV/AIDS (MOE, } \\
\text { 2003), guidelines }\end{array}$} & $\begin{array}{l}\text { Structures, open ended } \\
\text { questionnaires to principals, } \\
\text { teachers and parents (2003/4) }\end{array}$ & $\begin{array}{l}\text { Launch: Multivoiced planning } \\
\text { conference, capacity building, and } \\
\text { monitoring/evaluation activities } \\
\text { cohort 1,2,3,4 (Figure 1). }\end{array}$ & $\begin{array}{l}\text { Reports and minutes from the launch } \\
\text { (conference), capacity building, and } \\
\text { monitoring/evaluation activities }\end{array}$ \\
\hline $2002-2006$ & $\begin{array}{l}\text { HIV/AIDS documents } \\
\text { (I/NGOs), literature } \\
\text { reviews }\end{array}$ & $\begin{array}{l}\text { Project coordination team meetings, } \\
\text { field visits, reflection notes }\end{array}$ & $\begin{array}{l}\text { Province and districts meetings, } \\
\text { minutes and reports }\end{array}$ \\
\hline 2008 & & Re-visit to two district cohort A & \\
\hline
\end{tabular}

In order to code and categorize the huge amount of data, NVIVO, a qualitative data analysis (QDA), a computer software package, was used to categorize the qualitative data. The main categories that evolved were clustered around two main epistemological categories, the traditional kingdoms, the chiefs' structure including traditional practices, values and indigenous knowledge system, termed the chief community-based system and the scientific way of perceiving and understanding HIV / AIDS, represented by the western knowledge system, the school-community, Figure 2. CHAT was therefore applied as an analytical tool to deconstruct and give an in-depth understanding of the processes at play.

\subsection{Theoretical Framework}

Transformations and change, as illustrated in this study, demand a lengthy investigation process that can be supported with formative interventions. CHAT [5,6] was used to deconstruct data and identify the key contradictions within each domain of the two main interacting activity systems; the traditional chief structure, and the westernized system, the school/community activity system (see Figure 2).

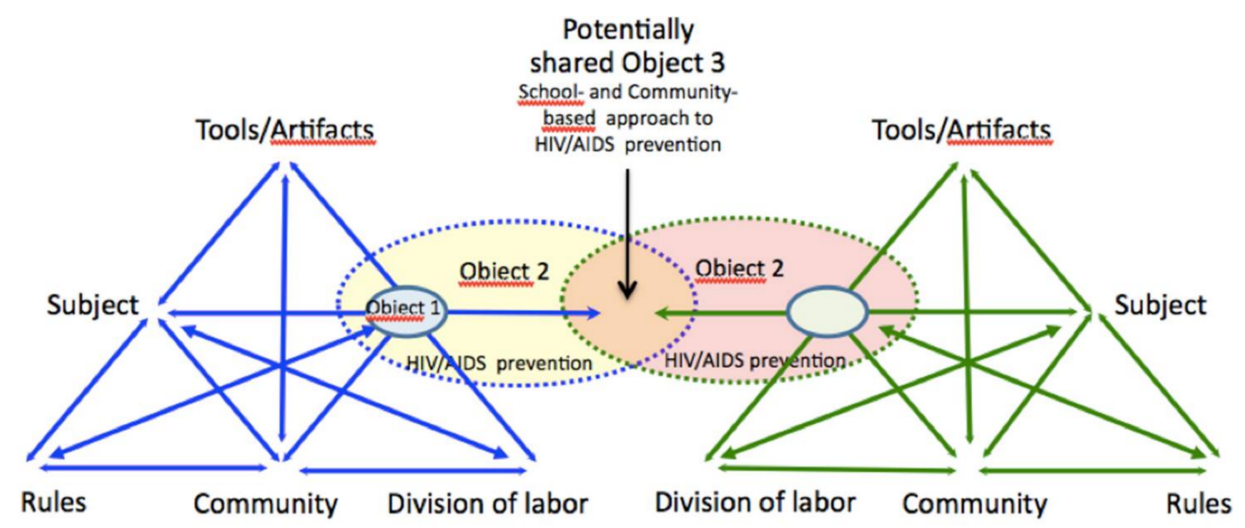

Figure 2. Two interacting activity systems, the school-community and the traditional, chief community system.

Figure 2 is an adaptation of Engeström's [5] theoretical concepts; it illustrates the two interacting activity systems. The chiefs and their parliament members, or head-men and head women, ruled the traditional kingdoms (i.e., their villages and communities), illustrated in Figure 1 as the traditional community. The rules and ascribed roles, practices, and responsibilities of the individuals living in traditional kingdoms were based upon indigenous knowledge systems (IKS), where status was related to age, gender, and bloodline, and guided by cultural, historical, and customary traditions. The structures and cultural artifacts were built upon the worldviews and daily routines of the 
traditional communities. The core mediating artifacts were based upon Wartofsky's framework (1973, in Cole, 1996 [10]), represented by a three-level hierarchy of artifacts. The primary artifact in this study was represented by the significant other, the legitimate spiritual leaders, e.g., the chiefs. The secondary and tertiary levels were worldviews, cultural norms, traditions, and the schema framing their thinking and actions, all of which mediated the school principals' immediate actions; in Bernstein's [7] terms, they were dominated by spiritual power. Each corner in the triangle represented each constituent element in the activity system.

The other interacting activity system, here represented by the Ministry of Education's (MOE) structures and governed by the educational rationale, with its regulations reflected through policies, strategies, and hierarchies, is also illustrated in Figure 1 as the school community. From a structural perspective, the mediating artifacts were the managerial procedures, institutional culture, professional knowledge, academic knowledge, syllabi, and teaching manuals. In Bernstein's [7] terms, the symbolic power inherent within the academic domain is dominated by academic knowledge (e.g., power).

These two competing power domains occurred between two co-existing activity systems (e.g., the school community and the traditional community) with different and contradictory symbolic power interacting with each other. Different perceptions and discourses on HIV/AIDS were reflected in the worldviews of the various stakeholders. For anyone, whether novice or professional (including teachers and lecturers), to talk openly about the actual HIV/AIDS educational context was considered to be breaking a cultural taboo and was the most influential force guiding their immediate actions. The employees within the MOE structures (e.g., the principals and teachers) were socialized within their traditional context, and their worldviews reflected their cultural and historical heritage. However, at the individual level, the professional obligations expected from them within the educational and rational domain were to follow the requirements from their District Education Board Secretary.

The two different activity systems illustrate these dilemmas. There seemed to be an inherent contradiction between implementing the MOE's [2] HIV / AIDS education prevention strategies, and the school community objective (Object 1). The traditional community, represented through the chiefs, the custodians of culture, and the traditions guiding the lives of the people in the communities, including the pupils, the parents and the villagers in general, were mediated through rites, schemas, and taboos. These cultural practices were among the actual drivers of the epidemic and there were no clear strategy developed in the traditional chief's structures identifying a clear HIV / AIDS mitigating strategy, thereby represented by an empty circle in Figure 2.

The interaction between these two activity systems further represents the overall framework used to analyze the findings: the existing HIV/AIDs prevention discourses, policies, strategies, and experienced realities among the core stakeholders. The ongoing collaboration, interactions, dialogues, and negotiations lead to a common negotiated HIV/AIDS mitigation strategy (Object 3 in Figure 2). In the following section, some of these interventions, their local solutions, and how a broader multiple stakeholder involvement contributed to relevant and localized solutions to mitigate the drivers of HIV / AIDS.

\section{Results}

\subsection{Perceptions and Experiences of HIV/AIDS Mitigation}

In the initial stages of the program, a needs analysis and other baseline activities were carried out to identify the needs, resistance, dichotomies, and dilemmas (i.e., contradictions) manifested through the voices and activities of the multiplicity of stakeholders in different contexts across and within the two activity systems. In this way, the study identified the matches and mismatches between local, national, and global approaches, as well as pinpointed areas of congruence and dissimilarity. The findings from the baseline surveys revealed mismatches between local contexts, worldviews, needs, and the national application of global HIV/AIDS strategies. 
During the inception period, the baseline surveys revealed that school principals were unaware of the MOE's HIV / AIDS policies and school-based strategies. All members of society at the time were experiencing the epidemic, and the principals expressed a sense of urgency toward trying to mitigate the effects. From their perspective, schools should play a leading role in fighting the disease. However, they were unable to speak openly in group presentations about the impacts of HIV / AIDS. They were caught between their professional obligations as educators and their cultural obligations; specifically, Zambian culture constrained open discussions about sex and sexuality as it related to HIV / AIDS.

The results from the baseline surveys conducted before the new intervention took place revealed that the stakeholders, from MOE officials at the district level to those working at the school level, were unaware of the existing policies and strategies regarding HIV/AIDS prevention education. They saw the importance of applying HIV / AIDS prevention as a part of the curriculum and syllabus, but they did not know how to implement it. In general, they lacked information about the MOE's prevention policies and strategies, syllabuses and guidelines regards HIV / AIDS education, and no training related to HIV / AIDS education had been offered except a few random workshops at MOE headquarters. Some schools had received some HIV/AIDS teaching kits from international and national NGOs or church related organizations, most of it without any contextual relevance.

\subsection{Contradictions and Their Manifestations}

Findings from meetings with principals, various school visits, and cluster meetings indicated that sociocultural and contextual conditions contributed to the factors considered to be drivers of the virus. Taboos were major barriers; it was inappropriate to speak freely about HIV / AIDS in school or in other public contexts. Any talk about HIV/AIDS was considered taboo because it were related to sex and sexuality, and breaking taboos led to stigmatization. People also believed the HIV / AIDS was caused by witchcraft, another reason for stigmatization. The cultural taboos kept people in silence, nobody talked openly about HIV / AIDS [8]. According to MOE directives, education officials were expected to include HIV/AIDS education prevention as a cross-cutting issues, in other words talk about sex and sexuality in relation to HIV/AIDS prevention education, but they were all heavily constrained by the cultural taboos.

The benefits of having the local chiefs participate in HIV / AIDS school-based outreach activities were clear. When the chiefs participated in college lectures, it seemed to contribute to the increased participation of parents and other community members in prevention activities. Their spiritual power as potential agents of change illustrated the importance of cultural artifacts, or the significant other, as a mediating tool. The diverse environmental landscapes and living conditions of each local community reflected the variety in their practices, particularly in terms of understanding the drivers of the epidemic. The need for a localized prevention strategy that was relevant to learners in different areas became a paramount concern.

The United Nations Agency for International Development (UNAIDS) and its global campaign against HIV / AIDS required that their recipient countries established a national cross-ministerial body to fight the epidemic. In Zambia this body was termed the National Aids Commission (NAC). But in Zambia, MOE's HIV / AIDS prevention strategies had applied a decentralized HIV / AIDS education prevention approach. The lack of a coordinated and holistic prevention approach between these two institutions created a complex and uncoordinated responsibility for implementing HIV / AIDS prevention strategies. The lack of communication between national and local institutions, even within the MOE's own employee base, was also identified as a major primary contradiction within the education sector itself (i.e., the school community's rules and division of labor). The MOE employees, the principals, and the teachers were expected to implement the policies, but they were uninformed about the existing HIV / AIDS prevention education policies and strategies, as were the Parent Teacher Association members. This illustrated a contradiction between the domains of rules and division of 
labor (see Figure 2), here reflecting a secondary contradiction, with the actual teaching strategies not forwarded to the implementers.

Engeström's [4] four core contradictions; primary, secondary, tertiary, and quaternary (as listed in Table 1) were reflected in the stakeholders' accounts during the inception period; Table 1 identifies some of the core contradictions and their manifestations. The primary and secondary contradictions are within and between the different domains covering the interacting activity systems (some representing a polyphony of contradictions). Externally driven strategies (e.g., duplicating HIV/AIDS prevention strategies), tertiary contradictions, and quaternary contradictions were reflected through external and opposing strategies. The perceptions and experiences of the HIV/AIDS prevention education context were clustered around the four core contradictions. They reflected the dissonance, gaps, and mismatches between policies and strategies and people's experiences of reality.

The baseline surveys illustrated how the meso-, exo-, and micro-level (Bronfenbrenner 1979, [11]) actors perceived the MOE's HIV / AIDS prevention education. The micro-level (local actors) did not have the required communication with the exo-level actor (the MOE). This was reflected through the ineffective interactions at the meso- and exo-level, contributing to a mismatch between intended macro-level policies/strategies and grassroots-level actions. At the same time, local practices enhancing the spread of HIV / AIDS and cultural practices and traditions reflected in the IKS were not taken into consideration, contradicting the ongoing educational HIV/AIDS prevention strategies.

In summarizing the contradictions revealed during the program inception, the baseline surveys revealed the main contradiction between the two interactive systems: cultural traditions versus scientific and rational approaches to HIV / AIDS mitigation. There were no formal collaboration between the two different activity-systems, Figure 2. The lack of involvement by chiefs further exacerbated this key contradiction. The culturally sensitive nature of the topic, the lack of shared information on policies and support initiatives on HIV / AIDS prevention education within the education sector, and the lack of coordination and shared objectives created additional contradictions.

\subsection{Contradictions and Their Negotiated Solutions}

The findings from the initial baseline surveys revealed a number of contradictions, key barriers to the implementation of a national HIV / AIDS education strategy. Based upon these findings, a multiple stakeholder workshop, Figure 1, was conducted. The overall aim was to share the various views and experiences with HIV/AIDS, reflecting the different worldviews and epistemological lenses, and reach to a common vision and strategy for mitigating HIV / AIDS locally, develop an alternative way forward. This opened up new modes of working across and within each of the two activity systems scrutinized: the traditional community and the school community.

In contrast to the top-down approach to HIV / AIDS prevention education spearheaded by the MOE, a bottom-up approach-a new object of activity and a localized HIV / AIDS education prevention strategy - was developed and implemented. It was based on dialogue and interaction across the two activity systems. An agreed collaboration across previous boundaries, where the diverse groups of stakeholders collectively identified the baseline situation, including needs and gaps, assessed optional strategies and ways forward through facilitating joint planning workshops, capacity-building activities, and monitoring and evaluation procedures. Sharing ideas and reflecting upon ongoing practices related to HIV / AIDS transmission, spread, and mitigation were rooted in local experiences and contexts featuring approaches similar to the principles of expansive learning $[4,5]$.

The processes and activities that defined the program approach, hereafter termed the Interactive School and Community Approach (ISACA), was mediated through a range of multi-voiced activities (i.e., primary tools or artifacts). The various ISACA sessions represented expansive learning spaces where sharing, mutual understanding, intentional reflection, innovation, and learning were introduced through explicit mediation by the core ISACA coordination team (the province level was represented by a senior planning officer and senior counselling officer, and in addition one head teacher and the external facilitator/researcher). 
The different worldviews, social norms, traditional rituals, and taboos (i.e., secondary artifacts) [10] were given the space to be openly questioned and discussed with the support and thereby explicit approval of the chiefs. New knowledge was constructed based upon multi-voiced interactions. Scientific knowledge and analytical evidence were contrasted with existing gender roles, taboos, and taboo-violating practices. Contradictions were identified, the way forward was negotiated, and the dialogues gradually turned into innovative and alternative solutions to reduce, alter, or eliminate practices enhancing the spread of the epidemic.

The MOE strategies (2003 [2,3]) required a teaching method featuring open critical dialogue on existing sexual practices enhancing the spread. This included scientific knowledge, but at the same time required that teachers opened up on talking about sexuality - which was a taboo-but also contesting existing cultural traditions and practices. However, the teachers who were to implement the policies contested this, as breaking the cultural norms were considered taboo, and put people and family members in the risk of being stigmatized. Their ambiguity due to existing cultural and traditional practices regulated through customary laws, taboos, stigmatization, and patriarchal structures were contradictory to an implementation of existing HIV / AIDS prevention education policies and teaching manuals, syllabuses and guidelines [3,4].

HIV/AIDS prevention education through formal education was another goal-driven activity involving artifacts to mediate teaching and integrated school and community activities. The various contradictions found their local and innovative solutions through dialogue, interaction and negotiations through collaboration and involvement of the various stakeholders. The contradictions and possible solutions evolved successively through workshops, sharing of trials and experiences during the program period. Those involved reached to new visions and solutions, e.g., objectives through core program activities, e.g., planning, capacity building, annual monitoring, and evaluation sessions, as well as internal field visits.

Actors from the two interacting activity systems developed the new objects of activity through collaboration and coordination. The MOE coordinated the main program activities and ensured close collaboration with relevant external NGO partners engaged in HIV/AIDS sensitization within the districts and schools, through the core team at the provincial level. The chiefs initiated activities within their traditional communities, originating from the House of Chiefs (the national body of the Zambian chiefs, who, according to the Zambian Constitution, are the custodians of culture and traditions) and trickling down to the village level. Utilizing both activity systems, organizational bodies and their relevant stakeholders used various initiatives, such as social vaccination, to mitigate the spread and impact of the epidemic.

The Province Education Officers provided financial support through MOE funding bodies; the overall mandate was to ensure that students and teachers had the knowledge and skills to avoid contracting HIV/AIDS, as well as to reduce stigmatization and taboos. This required the strategic training of District Education Office (DEO) representatives, principals, and teachers in order to guarantee that the HIV/AIDS prevention education was based upon the MOE's policies and strategies [2-4].

The chiefs, the country's spiritual leaders, acted as the significant others, as Weertch (1998 [12]) defines it; their contribution proved to be an important mediating artifact in the HIV/AIDS prevention approach analyzed in this study. Their role in giving permission to break cultural taboos, leading the transformation of cultural artifacts in the service of preventing the spread of HIV / AIDS, and caring for those with the disease informed the central themes of the approach. By leading the cultural change necessary to reducing the drivers of the spread of HIV / AIDS, the target audience was free to open up and participate in the approach to HIV/AIDS prevention that would ultimately lead to behavioral changes.

Tables 2 and 3 displays some of the main contradictions, as revealed in the baseline survey, their manifestations and solutions as they evolved during the negotiation and implementation (last column). 
Where the chiefs questioned initiation rites and challenged parents to discuss sexuality and HIV / AIDS with their children, the role of initiation with rites that put young people at risk of contracting the disease were changed, and in some cases, eliminated. As parents participated in the approach, they became more informed and gained permission from their traditional leaders to take responsibility for their children's growth and maturation; this caused new cultural patterns to emerge. Gyekye [13] argues that transformation and cultural change occurs over time, but the first step is for a generation to question the value of current traditions and practices. In this debate, that is exactly what the participants did. Various stakeholders' contributions, including the pupils' opinions and voices, showed how powerful such horizontal and vertical learning could actually be.

The facilitators, in this case, the Zambian MOE program coordinators, adhered to cultural and traditional norms when facilitating program activities. The approaches and processes reflected the epistemological lenses and worldviews of the participants when negotiating and agreeing upon a common vision of the new object of activity. In so doing, the horizontal interaction across traditional boundaries and activity systems contributed to cultural border crossing, innovative practices, and cultural and educational transformation. The stakeholders agreed that the MOE, through the HIV/AIDS coordination team, should oversee the intervention in order to ensure close collaboration between the partners from the two activity systems as well as other local partners.

The participants "voiced and named their world", collaborating in terms of agreeing upon their "here and now", or their present, existential, and concrete situation (Freire, 1972 in Collins, [14] 2011, p. 105). Such a process contributes to an active conscious engagement that changes both the world and the acting subject in an emancipatory direction. Chambers and Pettit, (2003 [15]). The inclusive and participatory process further illustrates what Smith (2007 [16]) describes as a decolonizing approach that enables everybody to take the perspective of the other.

The views and knowledge that the various participants (traditional leaders, the MOE employees, NGOs, pupils, teachers, parents, professionals, and novices) presented during the introductory workshops created a learning situation where traditional knowledge and practices were challenged and contested in the context of new knowledge about HIV/AIDS, its drivers, mitigation strategies, and educational policies.

At the global level, this study revealed that UNAIDS and PEPFAR (The US President's Emergency Plan for AIDS Relief), two influential global actors in HIV / AIDS prevention initiatives, both imposed strategies that were misaligned with Zambian national strategies and contextual realities regarding HIV / AIDS prevention needs and priorities. UNAIDS required the establishment of a cross-ministerial national commission, NAC, that in the Zambian context turned into a highly centralized body that contrasted with the overall decentralizing efforts of the MOE's strategies.

The lower-level institutions found UNAID's funding mechanisms to be too complicated to use, causing delays that hindered the implementation of HIV / AIDS preventive activities at lower-level institutions. In addition, UNAIDS had one global monitoring mechanism where indicators were mismatched with what was identified as the main drivers of HIV / AIDS in Zambia (UNGASS (United Nations General Assembly Special Session)) reports and could not be applied to measure existing local or national level interventions. In 2005, access to PEPFAR suddenly required a change in the overall Zambian strategy, excluding condom-based approaches that were a key component of the national Zambian prevention strategy.

In these examples, the external global funding bodies did not align with the overall national policies, strategies, and contextual realities in Zambia, causing confusion and challenges for the actors depending upon these funds; they illustrate the negative impact of applying global strategies. The global actors' approaches were to follow the top-down practices of historical applications of blueprints and of "more of the same" in development assistance, as argued by Klees [17] in their critique of global plans. 


\section{Discussion}

Creating the new object of activity can be described as follows:

- Structural and organizational change in the HIV/AIDS prevention in the province to include broad stakeholder involvement and horizontal collaboration between the two interacting activity systems

- Cultural change and transformation

- Implementation of HIV/AIDS education prevention through school- and community-level collaboration

Based upon the HIV/AIDS mitigation intervention described in the paper, the multi-voiced strategy, the identification of contradictions, their manifestations and negotiated solutions reveals some implications for future development work.

\subsection{Multi-Voiced Horizontal Collaboration}

Facilitating and mediating development strategies require contextual knowledge and alignment to cultural protocols in order for local actors to be involved and to be responsible for their own development and development strategies, and their object of activity, a possible third space. The inception, planning procedures, and agreed-upon rules were applied across the province. It reflected the same principles of multi-voiced collaboration and coordination within their existing structures involving employees and relevant resource personnel. Capacity-building and learning took place within and across the participating actors and institutions. After the interventions, the MOE employees and other participating actors sustained their new knowledge. The division of labor was characterized by coordination and a shared responsibility between the key actors in the two activity systems; the workshops were carried out collaboratively between the MOE staff down to the classroom and community levels. Throughout, the chiefs collaborated closely with all parties, sometimes through their Head Men, identified elderly leaders.

\subsection{School and Village Level}

At the school and village level, the traditional leaders' influence was of equal importance. Their involvement showed the principals, the teachers, and the pupils that they deemed educational settings to be safe zones for talking about sex and the HIV/AIDS epidemic. By working alongside the chiefs, and supported by the MOE, the stigma was significantly reduced. This enabled teachers to gradually move away from the "five-minute approach" to more interactive teaching practices that allowed for discussions of HIV/AIDS-related topics that were previously taboo.

Schools and their teachers worked with the chiefs to improve the link between the schools and the parents (i.e., the wider community). As a result, better learning environments were created and pupils were re-socialized. As Darnell and Hoem (1996) [18] argue, this strengthened the content and impact of the HIV / AIDS messages and enabled the pupils to disseminate HIV / AIDS information to their peers and parents. Teachers were gradually able to include relevant cultural aspects in their teaching, and the pupils contributed with their own experiences and views in their classroom interactions.

The artifacts mediating the transformations and changes are categorized below according to the theoretical concepts taken from Cole [10]. The chiefs emerged as key influencing actors, or significant other, and they contributed heavily to breaking or bending cultural barriers. As custodians of culture and tradition who hold a mandate from Zambia's House of Chiefs, there was no doubt about their legitimacy as leaders in their respective kingdoms and villages. This position empowered them to act as role models and gate openers. By talking openly about HIV / AIDS, the means of contracting and spreading the disease, and ultimately actively intervening to mitigate HIV / AIDS by using culture as a tool, the chiefs used their power to transform culture to protect their subjects. They led the way in changing cultural practices and fighting taboos. They also freed their followers to break the taboo, encouraging dialogue and interaction about drivers and mitigating strategies to reduce the spread of HIV / AIDS. 


\subsection{Role of Local Leaders and Cultural Implications}

As the significant other, or the auxiliary artifact [10], the chiefs played a crucial role in local development. In a society where traditional cultural norms still dominated people's worldviews and daily activities, trust and legitimate power played a much stronger role than in countries where cognitive and scientific knowledge dominated behavior and thought as argued by Hofstede (1996) [19] and Inglehardt (2005) [20]. Zambia, a collectivist society built upon sisterhood and brotherhood and trust among insiders, illustrates how culture actually contributes to and represents the mediating tools and artifacts in contexts where spiritual and indigenous knowledge dominate the norms guiding people's everyday activities, thoughts, and ethics. As explained by Cole [10] culture controls and mediates people's behavior and is a powerful means to mediate change, aligning with cultural practices and protocols when emphasizing change and transformation.

The chiefs abolished tertiary artifacts such as sexual cleansing, the subordination of women, and traditional cleansing and initiation processes. The chiefs used their parliament, with their senior head men/head women, and developed alternative rites, such as abolishing discriminatory content and praxes in the initiation ceremonies, and replacing sexual cleansing with herbal baths or back rubbing. As argued by Gausset 2001 [21], it is not a matter of abolishing culture, but it is a matter of preventing the spread of HIV / AIDS by adhering to safe behavioral patterns. The approach that was developed fully realized the importance of keeping up with the traditional rites whilst abolishing practices that were detrimental to people's health. The chiefs transformed culture to keep their people safe.

\section{Conclusions}

\subsection{Contributions to Development Research and Sustained Innovative Practices}

Using multiple research methods in a qualitative research paradigm across methodological traditions and professional boundaries, the research lead to the creation of knowledge contributing to a broader, in-depth understanding of development work. By combining CHAT and constructivist grounded theory, as Seaman 2008 [22] argues, these approaches to research increase the analytical possibilities, leading to robust explanations about cultural and social transformations

The complementarity of these main methodological approaches provided synergy for analyzing sociocultural activities that have received little attention where closer insights are desired. Developing a constructivist grounded theory on the basis of activity is a powerful approach to research that seeks greater ecological validity, as this kind of grounded theory of activity might be developed and employed at different levels of analysis and along different timescales depending on interest [11]. By adopting a constructivist grounded theory approach to activity theory research, the researcher was able to place herself in a dialectical relationship with the data as well, as with a theoretical point that offered methodological guidelines and assumptions. Constructivist grounded theory's compatibility with CHAT is best exemplified through the way in which CHAT provides tools for analyzing findings emerging from constructivist grounded theory. This complementarity generates new insights into activity-based research.

\subsection{CHAT, Power, Symbolic Control, and Transformation}

The two main interacting activity systems in the study were built upon different epistemologies: the rational, Western scientific perspective in contrast with the cultural, spiritual, and indigenous perspective. By using Engeström's [5,6] CHAT and Bernstein's [7,8] concepts of regulatory and symbolic control, this study revealed a deeper understanding of learning and transformative action at both the individual and system level. Engeström [5] argues that the main contradictions in any activity system are related to three dominant aspects of human activity: production, distribution, and exchange, where exchange and use value are the main contradictions.

Bernstein argues that the main contradictions are to be found in what guides behavior and determines people's way of living, referred to as symbolic control. Bernstein's [10] and Daniel's (2012) [23] theories 
give an added dimension to CHAT, highlighting the symbolic control of culture as well as academic and scientific power, all of which are important dimensions as integrated parts of the processes underlying any human interaction. They introduce symbolic power as a regulating and controlling force (i.e., the mediating artifacts). The dialogues and the interactions, or the processes scrutinized in the study, were highly influenced by the regulating power of cultural and spiritual artifacts; the primary, secondary, and tertiary mediating artifacts were reflected in culture and traditions, powerful means of guiding peoples' behavior and constituting symbolic power [10]. In this study, the symbolic power of culture manifested itself in how the cultural artifacts mediated people's lives, how culture guided and controlled their activities, and how expansive learning gradually changes their behavioral patterns exemplified in Tables 2 and 3.

Table 2. Types of Contradictions, Characteristics, and their Manifestations.

\begin{tabular}{lll}
\hline Contradictions & Characteristics & Manifestation \\
\hline $\begin{array}{l}\text { Primary contradictions: within } \\
\text { each corner (double bound) }\end{array}$ & $\begin{array}{l}\text { Notions of WK (Western scientific knowledge) } \\
\text { or IKS ways of perceiving and behaving; causes } \\
\text { and effects related to the HIV/AIDS epidemic }\end{array}$ & $\begin{array}{l}\text { Dilemmas on whether to adhere to cultural } \\
\text { norms and traditions or follow scientific } \\
\text { knowledge and recommendations regarding } \\
\text { the epidemic }\end{array}$ \\
\hline $\begin{array}{l}\text { Secondary contradictions: } \\
\text { between the corners of the } \\
\text { activity systems }\end{array}$ & $\begin{array}{l}\text { HIV/AIDS policy (rules) and its } \\
\text { implementation (division of labor) }\end{array}$ & $\begin{array}{l}\text { HIV/AIDS policies (rules) and mediating tools } \\
\text { (polyphony: cultural hindrances, lack of } \\
\text { teaching materials, lack of teacher training) }\end{array}$ \\
\hline $\begin{array}{l}\text { Tertiary contradictions: new object } \\
\text { of activities }\end{array}$ & $\begin{array}{l}\text { Cultural taboos, discussing HIV/AIDS in } \\
\text { public, stigmatization of people living with } \\
\text { HIV/AIDS }\end{array}$ & Not opening up \\
\hline & $\begin{array}{l}\text { Different preventive messages from various } \\
\text { I/NGOs (International/national } \\
\text { non-governmental organizations), CBOs } \\
\text { (Community-based organizations), as well as } \\
\text { faith organizations contrasting existing national } \\
\text { policies and strategies. }\end{array}$ & $\begin{array}{l}\text { Confusing and unclear messages to school } \\
\text { hincipals conflicting messages }\end{array}$ \\
$\begin{array}{l}\text { Quaternary contradiction: parallementation } \\
\text { and conflicting objects of activity }\end{array}$ & \\
\hline
\end{tabular}

Table 3. Contradictions, Manifestation and Solutions Emerging through Interactions.

\begin{tabular}{|c|c|c|}
\hline Type of Contradiction & Manifestation & Solution \\
\hline Primary contradiction (double bound) & $\begin{array}{l}\text { Dilemmas on whether to adhere to cultural } \\
\text { norms and traditions or follow scientific } \\
\text { knowledge and recommendations regarding } \\
\text { the epidemic }\end{array}$ & $\begin{array}{l}\text { Principals/teachers, opening up, } \\
\text { implementing contextualized HIV / AIIDS } \\
\text { education prevention, (the new object } \\
\text { of activity). }\end{array}$ \\
\hline Primary contradiction & $\begin{array}{l}\text { No formal collaboration between the two } \\
\text { activity-systems, chief and } \\
\text { school communities }\end{array}$ & $\begin{array}{l}\text { Applying a horizontal approach to } \\
\text { coordination between the two interacting } \\
\text { systems toward a common object of activity }\end{array}$ \\
\hline Tertiary contradiction & Not opening up & $\begin{array}{l}\text { Mitigating stigma and discussing HIV/AIDS } \\
\text { mitigation across activity systems, and in } \\
\text { public through community-involvement }\end{array}$ \\
\hline Quaternary contradictions & $\begin{array}{l}\text { Confusing and unclear messages to school } \\
\text { principals/teachers, conflicting } \\
\text { approaches/messages by different actors }\end{array}$ & $\begin{array}{l}\text { Commonly agreed localized strategy, } \\
\text { ensuring comprehensive district and } \\
\text { province approach }\end{array}$ \\
\hline
\end{tabular}

Engeström's [5] third generation of CHAT and Bernstein's [7] concepts of regulatory and symbolic power complement each other [23]. By merging these theories and building upon a constructivist and Vygotskian theoretical framework, we can reach to a broader understanding of how horizontal interaction across traditional boundaries may occur. Where Engeström [5,6] focuses on the outcomes of these processes, Bernstein $[7,8]$ focuses on the underlying interactive processes that come into play. In contrast to Engeström [5], Bernstein [8] specifically focuses on the importance of cultural artifacts and symbolic power when addressing the processes of development. 
This study revealed that transformation and change were based upon underlying power relations: a power struggle between spiritual versus academic/scientific power. Through explicit mediation and a broad participation of stakeholders different aspects of the spiritual versus scientific power, symbolic control, came into play, and through negotiations and dialogue, a common vision and strategy reflected the merging of IKS and WK manifested through the new objective of activities (i.e., the transformed practices).

\subsection{Reflections on Future Development Research}

This study highlighted contradictions between global and national responses to development challenges, and strategies developed locally, based upon culture and traditions. Globalization is an outcome of Western rationality and uses uniform information and technological tools to monitor complex programs worldwide; this has brought contradictory challenges to national development. Pushing standardized programs and monitoring tools on countries that depend heavily upon external support to meet the challenges and impacts, e.g., as in this study, mitigating HIV/AIDS may not create space for local actors to provide solutions. At the same time, new scientific knowledge, new technologies, and a multiplicity of learning opportunities play an increasingly important role in efforts initiated to improve equality and the well-being in all corners of the world.

\subsection{Decolonizing Approaches and Local Transformation}

Based upon the findings revealed in this study, national and local transformation can be graphically represented along two intersecting axes according to Storper (1996) [24] (see Figure 3). The $x$-axis represents initial practices surrounding the newly negotiated object of activity; the $y$-axis moves from traditional to a more advanced and complex societal order. A dynamic connection exists among the quadrants.

Each quadrant represents different ways of viewing and understanding development. Actors come from different "worlds" [24]: professional institutions, experts, novices, local chiefs, and head men/head women; they all represent different levels and layers of the society. Every "world" has culturally developed conventions, concepts and practices of managing interactions between and within its own constituency.

The four worlds in Figure 3 differentiate between competencies and skills needed to go beyond the existing understanding of the phenomenon. Quadrant 1 describes a scientific and rational epistemological understanding and Quadrant 2 illustrates knowledge based upon the historical and cultural development of expertise through IKS. Quadrant 3 reflects the world of global developmental strategies, and lastly, Quadrant 4 reflects the world of multi-voiced horizontal collaboration and development across professional borders and activity systems.

People need to find local solutions to their problems; it is therefore crucial to work with local actors to identify how one might meet the local challenges with relevant and effective tools and strategies. What cannot be dismissed when dealing with any individual or societal problem is the local culture and traditions. Culture in all forms guides and controls the behavior of populations; therefore, it is vital to understand what matters to people and to respect them wherever they are. This underscores the need for in-depth contextual understanding in order to apply culturally relevant and appropriate approaches to development work and/or research. A key contribution to the research in this study is the need for development efforts to embrace multi-voiced and participatory planning and processes by utilizing existing scientific knowledge to build upon local traditions and knowledge in order to reach relevant and appropriate responses by identifying a new negotiated object of activity, the third space.

The use of participatory and multi-voiced responses and facilitation within local protocols develops trust and acceptance. Decolonizing methodologies that focus on respecting and recognizing local voices and providing opportunities for an equal stake in their own development are empowering strategies that create local ownership [16]. These approaches anchor and sustain new development and transformation in the community and village development context, as revealed in this study. 
Rapid changes through new technologies, disasters including climate change, or epidemics like HIV/AIDS and Ebola require knowledgeable and skilled professionals to address challenges throughout the world. These professionals have to build upon the existing knowledge and needs as experienced by those acting upon new requirements, as illustrated by the vertical axis moving from traditional practices to a more advanced or new objective (see Figure 3). The concept of professional education must also reflect these new requirements.

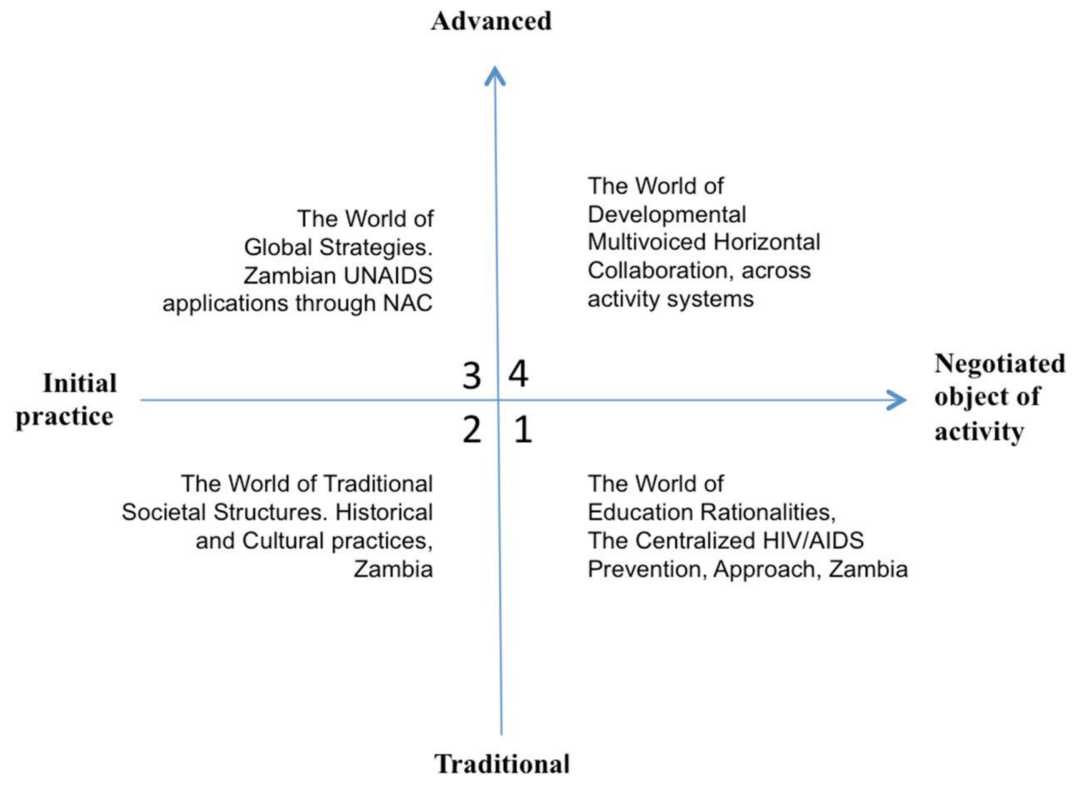

Figure 3. The world of education rationalities and the centralized HIV / AIDS prevention approach in Zambia.

Rapid local, national, and international changes require responsive environments that can build upon and merge various knowledge systems to reach transformative agency and motivation in order to find unified solutions to the challenges facing societies and communities. Reaching solutions to challenges requires professionals who embrace openness and a willingness to deliberately contest and go beyond the given status quo in the activity in which the subjects are involved. These processes ultimately include explicit and implicit learning. Tracing the evolution of learning through horizontal collaboration across professional borders and activity systems manifested through the expansion of the object of activity, as well as through decolonizing approaches, will ultimately contribute to a broader understanding of future development work. This helps us understand how local structures, cultural strengths and indigenous knowledge can be utilized to bring about positive, contextualized change and transformation.

Conflicts of Interest: The author declares no conflict of interest.

\section{References}

1. Carm, E. Caught in Culture (PhD) Caught in Culture? Cultural Transformation through HIV/AIDS Prevention Education in ZambiaComparative and International Education. University of Stockholm: Stockholm, Sweden, 2017. Available online: http:/ / www.diva-portal.org/smash/get/diva2:1065687/FULLTEXT01.pdf (accessed on 23 March 2018).

2. Ministry of Education. HIV/AIDS Education Program-BESSIP (2001-2006); Ministry of Education: Lusaka, Zambia, 2001.

3. Ministry of Education. HIV/AIDS Education Strategic Plan, Zambia, 2001-2005; Ministry of Education: Lusaka, Zambia, 2001. 
4. Ministry of Education. Interactive Methodologies. Manual for HIV/AIDS Prevention in Zambian Schools, 1st ed.; Ministry of Education: Lusaka, Zambia, 2003.

5. Engeström, Y. Learning by Expanding; Orienta-Konsultit Oy: Helsinki, Finland, 1987.

6. Engeström, Y. Expansive learning at work: Toward an activity theoretical reconceptualization. J. Educ. Work 2001, 14, 133-156. [CrossRef]

7. Bernstein, B. Symbolic control: Issues of empirical description of agencies and agents. Soc. Res. Methodol. 2001, 4, 21-33. [CrossRef]

8. Bernstein, B. Vertical and horizontal discourse: An essay. Br. J. Sociol. Educ. 2010, 20, 157-173. [CrossRef]

9. Charmaz, K. Grounded theory, objectivist and constructivist methods. In Handbook of Qualitative Research; Denzin, N.K., Lincoln, Y.S., Eds.; Sage: London, UK, 2000.

10. Cole, M. Cultural Psychology; Harvard University Press: London, UK, 1996.

11. Bronfenbrenner, U. The Ecology of Human Development: Experiments by Nature and Design; Harvard University Press: London, UK, 1979.

12. Wertsch, J.V. Pedagogy, symbolic control and identity: Theory, research, critique. Basil Bernstein. Lang. Soc. 1999, 27, 257-259. Available online: http:/ / www.jstor.org/stable/4168837 (accessed on 12 November 2013). [CrossRef]

13. Gyekye, K. Traditions and Modernity: Philosophical Reflections on the African Experience; Oxford University Press: Oxford, UK, 1997.

14. Collins, C. Reflections on CHAT and Freire's participatory action research from the West of Scotland: Praxis, politics, and the "struggle for meaningful life". Mind Cult. Act. 2011, 18, 98-114. [CrossRef]

15. Chambers, R.; Pettit, J. Shifting power to make a difference. In Inclusive Aid, Changing Power and Relationships in International Development; Groves, L., Hinton, R., Eds.; Earthscan: London, UK; Sterling, VA, USA, 2004.

16. Smith, L.T. Decolonizing Methodologies: Research and Indigenous Peoples; Zed Books Ltd.: London, UK; New York, NY, USA, 1999.

17. Klees, S.J. Presidential Address: Reflections on Theory, Method, and Practice in Comparative and International Education. CIES Newsletter. 2008. Number 147. Available online: http:/ / cies.us/newsletter/may08/index_ may08.htm (accessed on 23 March 2018).

18. Darnell, F.; Hoem, A. Taken to Extremes: Education in the Far North; Aschehaug AS: Oslo, Norway, 1996.

19. Hofstede, G. Cultures and Organizations. Intercultural Cooperation and its Importance for Survival; McGraw-Hill International: London, UK, 1991.

20. Inglehart, R.; Welzel, C. Modernization, Cultural Change, and Democracy: The Human Development Sequence; Cambridge University Press: Cambridge, UK, 2005.

21. Gausset, Q. AIDS and Cultural Practices in Africa: The case of the Tonga, Zambia, 2001. Soc. Sci. Med. 2001, 52, 509-518. [CrossRef]

22. Seaman, J. Adopting a grounded theory approach to cultural-historical research: Conflicting methodologies or complementary methods? Int. J. Qual. Methods 2008, 7, 1-17. [CrossRef]

23. Daniels, H. Institutional culture, social interaction and learning. Learn. Cult. Soc. Interact. 2012, 1, 2-11. [CrossRef]

24. Storper, M. Innovation as collective action: Conventions, products and technologies. Ind. Corp. Chang. 1996, 5, 761-790. [CrossRef]

(c) 2018 by the author. Licensee MDPI, Basel, Switzerland. This article is an open access article distributed under the terms and conditions of the Creative Commons Attribution (CC BY) license (http://creativecommons.org/licenses/by/4.0/). 